\title{
Young's Modulus of Concrete by using Steel Fibre and Hybrid Fibre Reinforced Concrete
}

\author{
Thendral Sundararasan, S.J.Mohan, Arunya.A
}

\begin{abstract}
This paper displays the quality and exhibitions of steel fiber fortified cement (SFRC) The steel fiber consider in the of snared end steel filaments. To read the youthful's modulus for concrete the fiber content measurements Vf extended from 0.5 to 2.0 percent of steel fibres,.10 blends included one control blend (without filaments) were arranged and tried in the research facility Less quantities of breaks were seen in fiber fortified high quality solid examples, which demonstrate an improved pliability with the expansion of strands in the network.
\end{abstract}

Keywords:-Hybridization, steel fiber, young's modulus.

\section{INTRODUCTION}

A few inquire about works have been done all through the world to create the mechanical properties and strength investigation of cross breed fiber fortified concrete. A portion of the reports have been displayed in this papers, [2-5] have announced that solidness study, corrosive protections, sulfate protections, salt water protections, water assimilation and quick chloride infiltrations test [1]Cangiano and Plizzari On sturdiness of steel filaments strengthened concrete, the two sorts of SFRC is researched with specific reference to solidify defrost obstruction with and without de-icing salts, carbonation opposition, chloride oxygen porousness The two kind of blend utilized for blend A , and blend B ,the evaluation concrete utilized 30,40,The blend An is portrayed by volume division of fiber is equivalent to $0.51 \%$ and blend B $0.77 \%$,commmerical low carbon snared steel strands used.[2] Ardeshana and Atulk Desai toughness of fiber fortified cement of marine structures, This paper shows a short best in class report on mechanical properties and solidness of fiber fortified solid, Addition of polypropylene triangular filaments improved toughness of cement. The misfortune in weight and misfortune/gain in compressive quality of the 3D shape examples improved with age. Compressive quality of solid increments with increment in

\footnotetext{
Revised Manuscript Received on October 22, 2019.

Thendral Sundararasan, Asistant Professor, Department Of Civil Engineering,,Bharath Institution of Higher Education And Research,TamilNadu, India Email: thendral.cs@gmail.com

S.J.Mohan, Asistant Professor,,Department Of Civil Engineering,,Bharath Institution Of Higher Education And Research,TamilNadu, India .Email: mohansjm@yahoo.com

Arunya.A, Asistant Professor,,Department Of Civil Engineering,,Bharath Institution Of Higher Education And Research,TamilNadu, India .Email: arunyaaaa@gmail.com
}

fiber measurements up to $0.3 \%$, at that point it begins diminishing. So the ideal rate fiber found from explore is 0.3\%.[3] Vaishali et al. (2011) the test results show that met kaolin can extensively diminish the penetrability of superior concrete. The different insights regarding the chloride particle penetrability test have been introduced in this paper. The Chloride Ion Permeability of HPC blends are low to medium when contrasted and conventional M20 grade concrete. The Chloride Ion Permeability increments with increment in W/B proportion. Subsequently, it is encouraged to utilize lower W/B proportions in creating HPC. The Chloride Ion Permeability esteem diminished significantly with increment in met kaolin content from 0 to $30 \%$ along these lines showing improved toughness with expanding met kaolin content.[4] the paper recognizes fiber mixes that exhibit most extreme compressive and split rigidity of cement. We reason that the compressive quality somewhere in the range of S0.6P0.4 and $\mathrm{S} 0.7 \mathrm{P} 0.3$ is increment high as contrast with other interim, Split Tensile Strength S0.8P0.2 Gives High Strength as contrast with other Combination. . M.Uyan, H.Yildirim, H.Eryaman [5] In this trial work the benefits of utilizing typical plasticizer is explored fourteen blends are made and tried, corrosive assault on examples is watched, the snared steel strands stuck together in packs were utilized, the test outcomes have a significant improvement in the functionality and in uniform dissemination an extensive increment in the compressive, flexural quality, improved opposition against acidic assault.

\section{MATERIALS AND MIX PROPORTIONS}

\section{Materials}

The bond utilized in solid blends was normal Portland concrete of 43 evaluations, fine total was regular waterway sand affirming to Zone II of IS 383:1970 with greatest size of under 4.75. Coarse total fulfills degree in Table 2 of IS 383:1970. The properties of super plasticizer are given in table 1fibers were utilized for present examination (I) Hooked steel strands $50 \mathrm{~mm}$ long . 
Table 1: Properties of Super plasticizer

\begin{tabular}{|c|l|}
\hline Appearance & Brown liquid \\
\hline Specific Gravity & $1.238-1.240$ \\
\hline Chloride content & Nil to BS 5075 \\
\hline Air entrainment & $\begin{array}{l}\text { Typically less than } 2 \% \\
\text { additional air is entrained } \\
\text { at normal dosages. }\end{array}$ \\
\hline Alkali content & $\begin{array}{l}\text { Typically less than } 72.0 \mathrm{~g} \\
\text { Na2O equivalent per liter } \\
\text { of admixture. }\end{array}$ \\
\hline
\end{tabular}

Table 2: Properties of Hooked steel fibers

\begin{tabular}{|l|l|}
\hline Fiber Length & 2 in $(50 \mathrm{~mm})$ \\
\hline Equivalent Diameter & $0.039 \mathrm{in}(1.0 \mathrm{~mm})$ \\
\hline Aspect Ratio & 50 \\
\hline Tensile strength & $152,000 \mathrm{psi}(1050 \mathrm{Map})$ \\
\hline Deformation & Hooked end(HE) \\
\hline Appearance & Bright and clean wire \\
\hline
\end{tabular}

\section{A. Mix Proportions}

Three kinds of cement blends were readied utilizing water-bond proportion of 0.4.The shape were loaded up with $0 \%$ HFRC, $0.5,1,1.5,2 \%$, of SFRC strands Concrete creation configuration is given in Table 4 . The rates of filaments are chosen dependent on the writing audit the measure of super plasticizer was chosen by swamp cone test which was $0.8 \%$ by weight of fastener to keep up the usefulness and the consistency of the blends. The blend plan of the regular plain solid blend (CC) is done by IS 10262:2009

Table: 4 Concrete composition design

\begin{tabular}{|c|c|c|c|}
\hline $\begin{array}{c}\text { Cement } \\
\mathrm{kg}^{3}\end{array}$ & $\begin{array}{c}\text { Fine aggregate } \\
\mathrm{kglm}^{3}\end{array}$ & $\begin{array}{c}\text { Coarse } \\
\text { aggregate } \mathrm{kgm}^{3}\end{array}$ & Water $\mathrm{m}^{3}$ \\
\hline 395 & 669.24 & 1235.52 & 158 \\
\hline 1 & 1.69 & 3.13 & 0.4 \\
\hline
\end{tabular}

\section{SCOPE AND OBJECTIVES}

\section{Objectives}

This papers is proposed to think about the mechanical properties on fibere fortified cement, the filaments distinctive rate and diverse blend can be added the solid and to consider the qualities of regular solid, steel fiber and half and half fiber strengthened cement, to assess the presentation of customary solid, steel fiber and cross breed fiber strengthened cement by non ruinous testing.

\section{Methodology}

A blend proportioning to be finished by regular preliminary blending approaches for, wanted droop esteem Study, the chamber size distance across $150 \mathrm{~mm}$ Length $300 \mathrm{~mm}$, crystal $100 \times 100 \times 500$, at last think about the outcomes for traditional solid, steel filaments and half and half strands.

\section{TEST METHODS}

The trial programs were to, in the mechanical properties of new and solidified state fiber strengthened cement with various blend and distinctive level of filaments were arranged and tried in the lab and the test was performed on shapes tests of $150 \mathrm{~mm}$, chamber $150 \times 300 \mathrm{~mm}$, with 0.8 rates of super plasticizer and in water relieving for 7 and 28 days under controlled research facility.

\section{RESULTS AND DISCUSSION}

Level of steel strands expanded in the volume of blend, it expanded the compressive strength,the steel fiber and demonstrated great protections from penetrability at age of 28 days as for regular concrete. The nature of solid normal bounce back number and the ultrasonic heartbeat speed for a wide range of cement (ordinary, steel fiber, half breed fiber) is the reasonable and great solid quality.

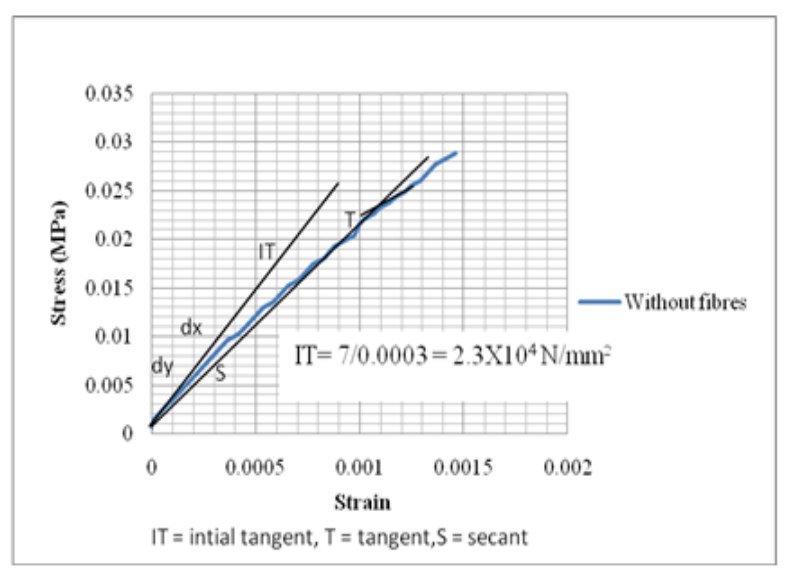

Fig 1. Young's Modulus for without fibres

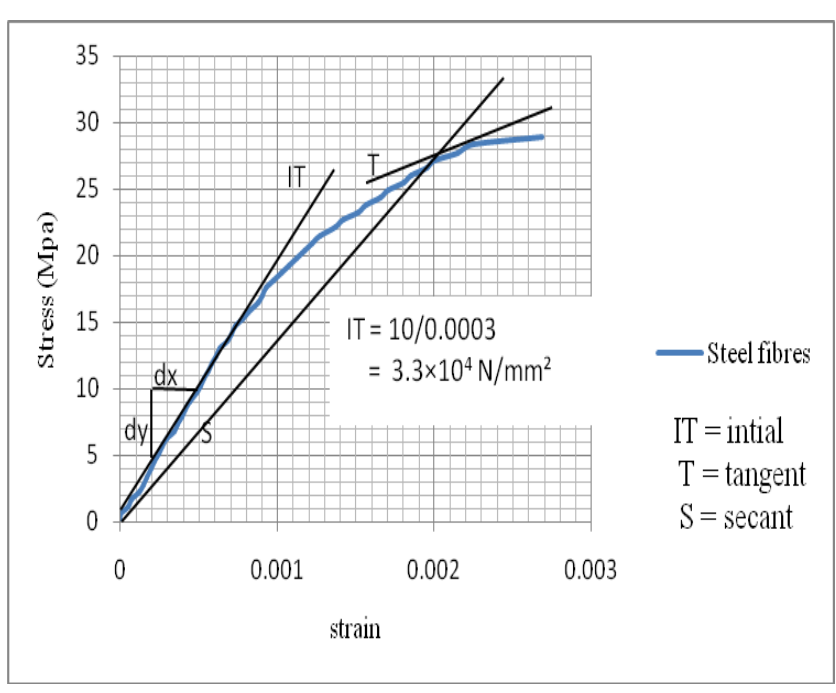

Fig 2. Young's Modulus for steel fibres

Published By:

Blue Eyes Intelligence Engineering 


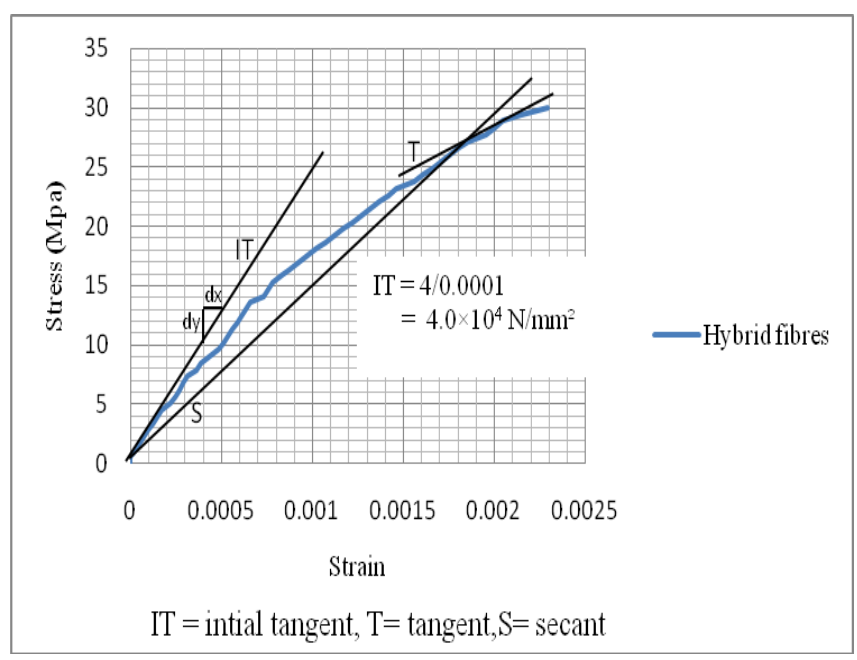

Fig3. Young's Modulus for hybrid fibres

\section{CONCLUSION}

In the steel fiber demonstrated great protections from porousness at age of 28 days regarding customary cement. Expansion of steel fiber will be superb in the corrosive opposition, sulfate protections, and salt protections, on the grounds that the loss of compressive quality was not exactly when contrasted with deference with customary cement. The normal bounce back sledge numbers for water assimilation, corrosive, sulfate, salt, in the before inundation separately by steel fiber and crossover fiber which were $5.2 \%, 2.73 \%, 3.98 \%, 15.22 \%$ and $4.76 \%, 1.89 \%$, $4.82 \%, 14.34 \%$ higher regarding customary cement. The normal bounce back sledge numbers for water ingestion, corrosive, sulfate, salt, in the after submersion individually by steel fiber and half and half fiber which were $0.8 \%, 2.27 \%, 4.82 \%, 8.87 \%$ and $\quad 5.2 \%, 4.83 \%, \quad 4 \%, 6.82 \%$ higher as for ordinary cement. The normal ultrasonic heartbeat speeds for water assimilation, corrosive, sulfate, salt, in the before inundation separately by steel fiber. The normal ultrasonic heartbeat speeds for water retention, corrosive, sulfate, salt, in the after drenching separately by steel which were $0.8 \%, 1.05 \%, 1.50 \%, 1.9 \%$ and $3.06 \%, 1.75 \%$, $2.77 \%, 1.9 \%$ higher as for traditional cement. Less quantities of splits were seen in fiber fortified high quality solid examples, which demonstrate an improved pliability with the expansion of filaments in the grid.

\section{REFERENCES}

1. Iyappan L., Dayakar P., Identification of landslide prone zone for coonoortalukusing spatial technology, International Journal of Applied Engineering Research,V-9,I-22,PP-5724-5732,Y-2014.

2. Kumar J., Sathish Kumar K., Dayakar P.,Effect of microsilica on high strength concrete, International Journal of Applied Engineering Research,V-9,I-22,PP-5427-5432,Y-2014.

3. Dayakar P., Vijay Ruthrapathi G., Prakesh J., Management of bio-medical waste, International Journal of Applied Engineering Research,V-9,I-22,PP-5518-5526,Y-2014.

4. Swaminathan N., Dayakar P., Resource optimization in construction project, International Journal of Applied Engineering Research,V-9,I-22,PP-5546-5551,Y-2014.
5. Venkat Raman K., Dayakar P., Raju K.V.B.,An experimental study on effect of cone diameters in penetration test on sandy soil, International Journal of Civil Engineering and Technology,V-8,I-8,PP-1581-1588,Y-2017.

6. Saritha B., Chockalingam M.P.,Photodradation of malachite green DYE using TIO2/activated carbon composite,International Journal of Civil Engineering and Technology,V-8,I-8,PP-156-163,Y-2017

7. Shendge R.B., Chockalingam M.P., Saritha B., Ambica A.,Swat modelling for sediment yield: A case study of Ujjani reservoir in Maharashtra, India,International Journal of Civil Engineering and Technology,V-9,I-1,PP-245-252,Y-2018

8. Chockalingam M.P., Balamurgan V.,Modernisation of an existing urban road-sector in Chennai, a case study report,International Journal of Civil Engineering and Technology,V-8,I-8,PP-1457-1467,Y-2017

9. Saritha B., Chockalingam M.P.,Adsorption study on removal of basic dye by modified coconut shell adsorbent, International Journal of Civil Engineering and Technology,V-8,I-8,PP-1370-1374,Y-2017

10. Saritha B., Chockalingam M.P.,Adsorptive removal of heavy metal chromium from aqueous medium using modified natural adsorbent,International Journal of Civil Engineering and Technology,V-8,I-8,PP-1382-1387,Y-2017

11. Chockalingam M.P., Palanivelraja S.,Retrospective analysis of a theoretical model used for forecasting future air quality near the north Chennai thermal power plant,International Journal of Civil Engineering and Technology,V-8,I-8,PP-1457-1467,Y-2017

12. Saritha B., Chockalingam M.P.,Photodegradation of methylene blue dye in aqueous medium by $\mathrm{Fe}-\mathrm{AC} / \mathrm{TiO} 2$ Composite,Nature Environment and Technology,V-17,I-4,PP-1259-1265,Y-2018

13. Shendge R.B., Chockalingam M.P., Kaviya B., Ambica A.,Estimates of potential evapotranspiration rates by three methods in upper Bhima Basin, In Maharashtra, India,International Journal of Civil Engineering and Technology,V-9,I-2,PP-475-480,Y-2018

14. Shendge R.B., Chockalingam M.P.,The soil and water assessment tool for Ujjani Reservoir,International Journal of Mechanical Engineering and Technology,V-9,I-2,PP-354-359,Y-2018

15. Shendge R.B., Chockalingam M.P.,A review on soil and water assessment tool,International Journal of Mechanical Engineering and Technology,V-9,I-2,PP-347-353,Y-2018

16. Sachithanandam P., Meikandaan T.P., Srividya T.,Steel framed multi storey residential building analysis and design,International Journal of Applied Engineering Research,V-9,I-22,PP-5527-5529,Y-2014

17. Meikandaan T.P., Ramachandra Murthy A.,Study of damaged RC beams repaired by bonding of CFRP laminates,International Journal of Civil Engineering and Technology,V-8,I-2,PP-470-486,Y-2017

18. Meikandaan T.P., Ramachandra Murthy A.,Retrofittng of reinforced concrete beams using GFRP overlays, International Journal of Civil Engineering and Technology,V-8,I-2,PP-423-439,Y-2017

19. Meikandaan T.P., Ramachandra Murthy A.,Flexural behaviour of RC beam wrapped with GFRP sheets,International Journal of Civil Engineering and Technology,V-8,I-2,PP-452-469,Y-2017

20. Meikandaan T.P., Murthy A.R.,Experimental study on strengthening of rc beams using glass Fiber,International Journal of Civil Engineering and Technology,V-9,I-11,PP-959-965,Y-2018

21. Meikandaan T.P., Hemapriya M.,Use of glass FRP sheets as external flexural reinforcement in RCC Beam,International Journal of Civil Engineering and Technology,V-8,I-8,PP-1485-1501,Y-2017

22. Saraswathy R., Saritha B.,Planning of integrated satellite township at Thirumazhisai,International Journal of Applied Engineering Research,V-9,I-22,PP-5558-5560,Y-2014

23. Saritha B., Ilayaraja K., Eqyaabal Z.,Geo textiles and geo synthetics for soil reinforcement,International Journal of Applied Engineering Research,V-9,I-22,PP-5533-5536,Y-2014

24. Ambica A., Saritha B., Changring G., Singh N B., Rajen M., Salman Md.,Analysis of groundwater quality in and around Tambaram taluk, Kancheepuram district,International Journal of Civil Engineering and Technology,V-8,I-8,PP-1362-1369,Y-2017

25. Arunya A., Sarayu K., Ramachandra Murthy A., Iyer N.R.,Enhancement of durability properties of bioconcrete incorporated with nano silica,International Journal of Civil Engineering and Technology,V-8,I-8,PP-1388-1394,Y-2017 
26. Ilayaraja K., Krishnamurthy R.R., Jayaprakash M., Velmurugan P.M., Muthuraj S.,Characterization of the 26 December 2004 tsunami deposits in Andaman Islands (Bay of Bengal, India),Environmental Earth Sciences,V-66,I-8,PP-2459-2476,Y-2012

27. Ilayaraja K.,Morphometric parameters of micro watershed in Paravanar sub-basin, Cuddalore District,International Journal of Civil Engineering and Technology,V-8,I-8,PP-1444-1449,Y-2017

28. Ilayaraja K., Singh R.K., Rana N., Chauhan R., Sutradhar N.,Site suitability assessment for residential areas in south Chennai region using remote sensing and GIS techniques,International Journal of Civil Engineering and Technology,V-8,I-8,PP-1468-1475,Y-2017

29. Ilayaraja K., Reza W., Kumar V., Paul S., Chowdhary R.,Estimation of land surface temperature of Chennai metropolitan area using Landsat images,International Journal of Civil Engineering and Technology,V-8,I-8,PP-1450-1456,Y-2017

30. Chitra R.,Experimental study on beam using steel fiber and latex,International Journal of Civil Engineering and Technology,V-8,I-8,PP-1395-1403,Y-2017

31. Chitra R.,Analysis of traffic and management at Kovilambakkam intersection,International Journal of Civil Engineering and Technology,V-8,I-8,PP-1433-1443,Y-2017

32. Aswathy M.,Experimental study on light weight foamed concrete,International Journal of Civil Engineering and Technology,V-8,I-8,PP-1404-1412,Y-2017

33. Aswathy M.,Wastewater treatment using constructed wetland with water lettuce (Eichornia Crasipies),International Journal of Civil Engineering and Technology,V-8,I-8,PP-1413-1421,Y-2017

34. Kiruthiga K., Anandh K.S., Gunasekaran K, Assessment of influencing factors on improving effectiveness and productivity of construction engineers, 2015, International Journal of Applied Engineering Research, V - 10,I -17,p -13849-13854.

\section{AUTHORS PROFILE}

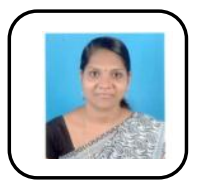

Thendral Sundararasan, Asistant Professor, Department Of Civil Engineering,,Bharath Institution of Higher Education And Research,TamilNadu, India

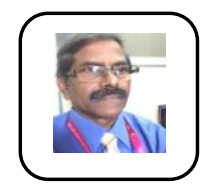

S.J.Mohan Professor,,Department Of Civil Engineering,,Bharath Institution Of Higher Education And Research,TamilNadu, India

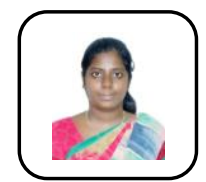

Arunya.A, Asistant Professor,,Department Of Civil Engineering,,Bharath Institution Of Higher Education And Research,TamilNadu, India 